\title{
Myopia in premature babies with and without retinopathy of prematurity
}

\author{
I. NISSENKORN, Y. YASSUR, D. MASHKOWSKI, I. SHERF, AND I. BEN-SIRA \\ From the Beilinson Medical Center, Department of Ophthalmology, Petah Tikva, Israel
}

SUMMARY One hundred and fifty-five premature infants weighing 600-2000 g were followed up during 1974-80 for the presence of retinopathy of prematurity (ROP) and for the existence of myopia. $50 \%$ of the premature infants who had ROP were myopic, while only $16 \%$ myopic premature infants were found among those who did not have ROP. There was a positive correlation between the degree of myopia and the severity of cicatricial ROP. No difference existed in the frequency and degree of myopia between premature infants in which ROP cicatrised spontaneously and in those where it cicatrised after cryopexy.

Myopia is a frequent finding in premature babies. ${ }^{1-6}$ Comparative studies $^{2-6}$ showed that premature infants tend to develop myopia and that there is a close relationship between myopia and retrolental fibroplasia. However, the relationship has not been clearly established.

In the present study we investigated the prevalence of myopia in premature infants and its relation to the cicatricial stages of ROP in untreated eyes and in eyes treated by cryopexy.

\section{Material and methods}

One hundred and fifty-five premature babies weighing from 600 to $2000 \mathrm{~g}$, born in 1974-80, were examined for the presence of ROP and for the existence of myopia at the age of 2 weeks; they were followed-up for 2-8 years, the mean follow-up time being 3 years. The family history was taken, and the premature babies with one or both parents myopic above $-6 \cdot 0$ dioptres were excluded from the study. The examination included indirect ophthalmoscopy and retinoscopy, and in 10 out of 26 eyes in which the myopia exceeded -3.0 dioptres a measurement of the axial length of the globe was performed by Amode ultrasound. Cycloplegia for retinoscopy was achieved by instilling cyclopentolate $0.5 \%$ (tropicamide) at intervals of 10 minutes, and retinoscopy was performed after $40-45$ minutes. All the children were examined and followed up by the same 2 examiners, who were senior paediatric ophthalmologists.

Correspondence to I. Nissenkorn. MD.
To obtain a complete view of the retinal periphery phenylephrine $5 \%$ was also instilled into the eyes of the premature babies. In eyes with ROP its cicatricial

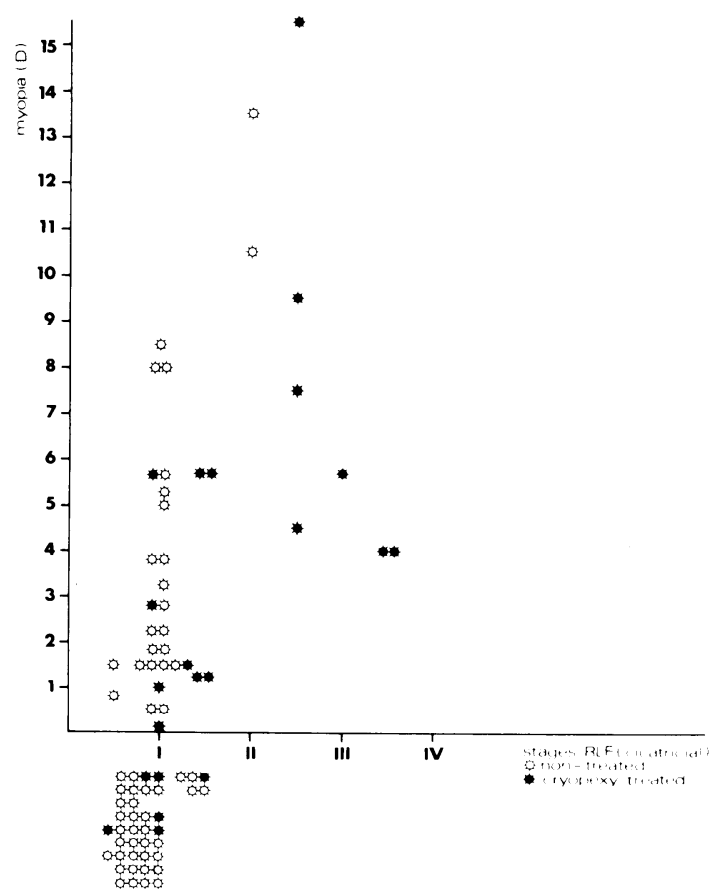

Fig. 1 Relation of ROP cicatricial stage and degree of myopia in untreated and in cryopexy-treated eves. The cases below the line represent the eves which were emmetropic and hypermetropic. 


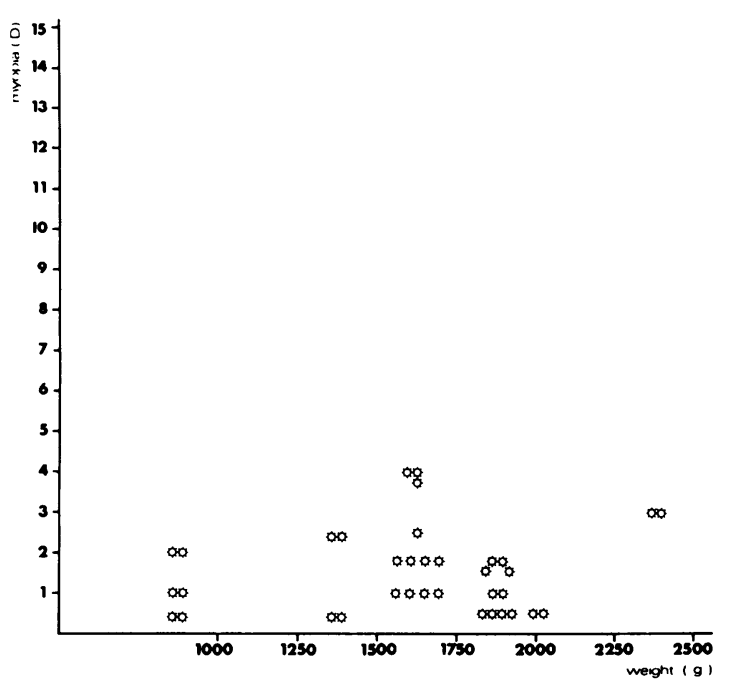

Fig. 2 Relation between birth weight and degree of myopia in premature babies without $R O P$.

Table 1 Myopia among the premature infants with and without ROP

\begin{tabular}{llll}
\hline & Myopia & No myopia & Total \\
\hline ROP & 21 & 21 & 42 \\
No ROP & 18 & 95 & 113 \\
Total & 39 & 116 & 155 \\
\hline
\end{tabular}

state was periodically correlated with the degree of myopia.

Sixteen patients ( 22 eyes) were treated by cryopexy, the criterion for treatment being ROP active stage II or more, according to Patz's classification. ${ }^{7}$ Seven treated eyes had ROP active stage II and 4 treated eyes had ROP stage II-III; in 3 treated eyes the ROP stage was more than active stage III (Fig. 1). One premature infant underwent retinal detachment operation in one eye.

\section{Results}

Of the 155 premature infants 42 had ROP and 113 did not. Of the 42 premature infants with ROP $21(50 \%)$ had myopia between -0.25 and -15.5 dioptres, with an average of -4.0 dioptres. Of the 113 without ROP

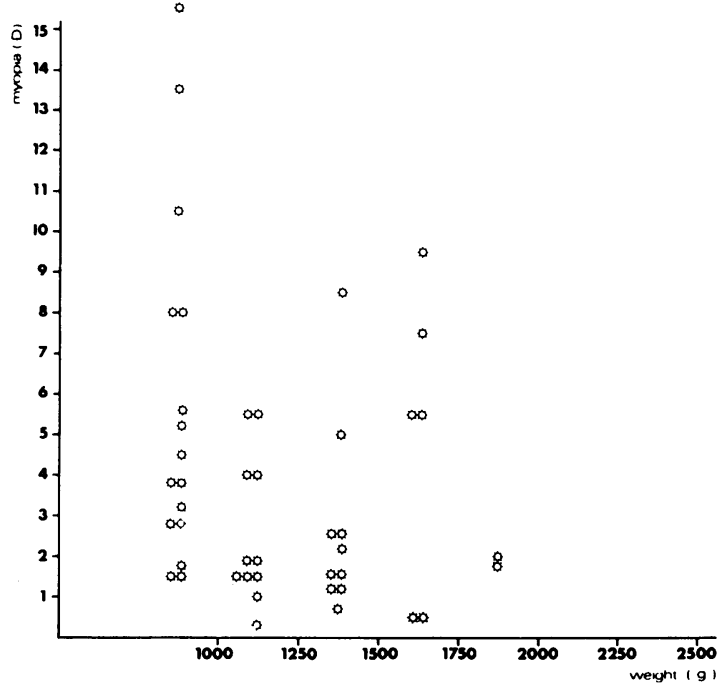

Fig. 3 Relation between birth weight and degree of myopia in premature babies with ROP.

only $18(15.9 \%)$ had myopia, which varied from $-0 \cdot 25$ to $-4 \cdot 0$ dioptres, with an average of $-1 \cdot 5$ dioptres.

There was a significant correlation between the prevalence of myopia and $\operatorname{ROP}\left(\chi^{2}=17 \cdot 11, p<0 \cdot 001\right)$. The degree of myopia in the eyes which had ROP was greater than in the eyes which did not have ROP, and this was also statistically significant $(t=2 \cdot 64$, $\mathrm{p}<0.001$ ) (Table 1).

As to the correlation between myopia and birth weight, most of the cases of myopia among children without ROP (Fig. 2) were distributed among those with a birth weight of $1000-1500 \mathrm{~g}$ (with an average myopia of -1.5 dioptres). In this group no statistically significant relationship was found between the extent of myopia and the birth weight (Table 2).

Among children with ROP (Fig. 3) most cases of myopia were in infants with birth weights between 750 and $1350 \mathrm{~g}$ (the average myopia being $-4 \cdot 0$ dioptres). Again, there was no difference from this point of view between untreated and cryopexytreated ROP eyes (Tables 3, 4, 5). In this group of children with ROP, treated and untreated, there was a statistically significant correlation between the birth

Table 2 Degree of myopia in premature infants without ROP according to birth weight (median, $-1.00 \mathrm{D}$ )

\begin{tabular}{lllllll}
\hline $\begin{array}{l}\text { Birth weight } \\
(\mathrm{g})\end{array}$ & $<1251$ & $1251-1500$ & $1501-1750$ & $1751-2000)$ & $2001-250)$ & Total \\
\hline $\begin{array}{l}\text { Number of eyes } \\
\text { Mean myopia (dioptres) }\end{array}$ & 6 & 4 & 12 & 12 & 2 & 36 \\
\hline
\end{tabular}


Table 3 Degree of myopia in cryopexy-treated and in untreated eyes with ROP (median, $-2 \cdot 00 \mathrm{D})$

\begin{tabular}{llll}
\hline & Cryopexy-treated & Untreated & Total \\
\hline Below median & 5 & 11 & 16 \\
Above median & 4 & 12 & 16 \\
Total & 9 & 23 & 32 \\
Mean (D) & $2 \cdot 72$ & $3 \cdot 15$ & \\
\hline
\end{tabular}

Table 4 Degree of myopia in cryopexy-treated and in untreated eyes with ROP (median, -0.5 D)

\begin{tabular}{llll}
\hline & Cryopexy-treated & Untreated & Total \\
\hline Below median & 7 & 22 & 29 \\
Above median & 8 & 21 & 29 \\
Total & 15 & 43 & 58 \\
Mean (D) & 1.63 & 1.61 & \\
\hline
\end{tabular}

Table 5 Degree of myopia in cryopexy-treated and in untreated eyes with ROP (median, $-10 \cdot 0 \mathrm{D})$

\begin{tabular}{llll}
\hline & Cryopexy-treated & Untreated & Total \\
\hline Below median & 0 & 3 & 3 \\
Above median & 2 & 1 & 3 \\
Patient number & 2 & 4 & 6 \\
Mean (D) & $2 \cdot 0$ & $9 \cdot 25$ & \\
\hline
\end{tabular}

weight and the extent of myopia $\left(\chi^{2}=11 \cdot 93, p<0 \cdot 02\right)$. and the average myopia gradually declined alongside with the increase of birth weight (Table 6). Fig. 1 also shows that the myopic dioptres of premature infants weighing less than $1000 \mathrm{~g}$ were above the median, while in premature infants weighing more than $1000 \mathrm{~g}$ the myopic dioptres were almost always below the median except in the group of children weighing between 1500 and $1750 \mathrm{~g}$.

Thirty-seven premature infants ( 71 eyes) were found to have evident signs of cicatricial stages of ROP. Stage I, 32 (62 eyes); stage II, 3 (6 eyes); stage III, 2 ( 3 eyes). Of these infants, 18 ( 30 eyes) in stage I were hypermetropic or emmetropic, while the other 19 who had cicatricial stage I, II, and III were myopic. The myopia varied from -0.25 to -8.25 dioptres (average -3.02 dioptres in stage I, and from -4.0 to -15.5 dioptres (average -8.27 dioptres) in stages II and III (Fig. 1).

\section{Discussion}

Clinical observations agree that ROP is almost always bilateral, though it may be much more advanced in one eye than in the other. ${ }^{2}$ The end cicatricial stages of the disease are usually established 4 to 6 months after the appearance of the active stages. ${ }^{5}$

The presence of myopia and its degree have been previously correlated with the severity of the early retinal changes during the phase of active ROP and later with the cicatricial phase, and it was demonstrated that eyes affected with ROP were most often myopic. ${ }^{8}$ However, a conclusion as to the exact correlation between the various stages of the active and cicatricial disease and the degree of myopia has not yet been clearly drawn, either in the natural history of the disease or in cryopexy-treated eyes.

The prevalence of myopia in the general population according to different authors varies from 5 to $18 \% \cdot{ }^{8-13}$ In a follow-up of a group of school children ${ }^{13}$ who weighed less than $1816 \mathrm{~g}$ at birth Zaharias et al. ${ }^{8}$ demonstrated a definite increased prevalence of myopia in those who had ROP. In one-third of the children of this group there were signs of active ROP during the first month of life, and $32 \%$ of them were myopic, while in the remaining two-thirds of the children of this group who did not have ROP only $4 \%$ were myopic.

Birge ${ }^{9}$ reported 7 cases of moderate to severe myopia in surviving premature infants in whom ophthalmoscopy revealed some degree of cicatricial stages of ROP. Other investigators ${ }^{10-13}$ showed that cicatricial ROP usually results in permanent myopia. Early myopia in premature infants without a hereditary predisposition may represent the sequela of mild undiagnosed ROP which has regressed.

As our study showed, there was a considerable difference between the existence and severity of the myopia between the premature infants with and without ROP. Moreover, there was a positive correlation between the degree of myopia and the cicatricial stage. It is true that most of the cases of myopia (32 eyes) had cicatricial stage I, and in them the myopia was between $-0 \cdot 25$ and $-8 \cdot 25$ dioptres, with an average of -3.02 dioptres. However, as the cicatricial stage advanced, the myopia became more severe, between $-4 \cdot 0$ and $-15 \cdot 5$ dioptres, with an average of $-8 \cdot 27$ dioptres (Fig. 1).

Table 6 Relation between degree of myopia and birth weight in premature infants with ROP (median, $-2 \cdot 75$ D)

\begin{tabular}{lllllll}
\hline $\begin{array}{l}\text { Birthweight } \\
(\mathrm{g})\end{array}$ & $<1001$ & $1001-1250$ & $1251-1500$ & $1501-1750$ & $1751-2000$ & Total \\
\hline $\begin{array}{l}\text { Number of eyes } \\
\text { Mean myopia (dioptres) }\end{array}$ & 16 & 10 & 10 & 4 & 2 \\
\hline
\end{tabular}


Treatment with cryopexy did not influence the relation between the cicatricial stage and the degree of myopia. This is shown in Fig. 1 and in Tables 3, 4 and 5 , where the distribution of myopia, related to the cicatricial stage, does not show any statistical difference between treated and untreated eyes.

Whether myopia in ROP is axial, corneal, or lenticular is still questionable. ${ }^{11-14} \mathrm{We}$ could not draw solid conclusions on this issue because we performed axial measurements by A-mode ultrasound and keratometry only in a limited number of eyes (10 eyes). However, these measurements showed that myopic eyes sometimes had an axial length within the range of hypermetropic or emmetropic true for the age of the patient ${ }^{13}$ while other eyes were sometimes emmetropic in spite of the fact that the axial length was within the range of myopia for that age. Thus a variety of factors may be involved in the myopia, but the issue needs to be further investigated.

Our thanks are due to S. Reisner. MD. chief of the Neonatal Intensive Care Unit, and R. Krickler. MD.

\section{References}

1 Curtin BY. Myopia: a review of its etiology. pathogenesis and treatment. Surv Ophthalmol 1970; 15: 1-17.
2 Fletcher MC. Brandon S. Myopia of prematurity. Am J Ophthalmol 1955: 40: 474-81.

3 Graham MV. Gray OP. Refraction of premature babies' eyes. $\mathrm{Br}$ Med J 1963: i: 1452-4.

4 Sharf J. Zoniss S. Zeltrer M. Refraction in premature babies. A prospective study. J Pediatr Ophthal 1978; 15: 48-50.

5 Gregory J. Retinopathy of prematurity in children in whom the disease has not progressed to complete blindness and the subsequent investigation of cases of myopia. Br J Ophthalmol 1957; 41: $321-7$.

6 Shapiro A. Yankol L. Nawratzki J, et al. Refractive power of premature children at infancy and early childhood. $A m$ J Ophthalmol 1980; 90: 234-8.

7 Patz A. Retrolental fibroplastia. Surv Ophthalmol 1969; 14: 1-29.

8 Zaharias L. Chrisholm VF. Chapman RB. Visual and ocular damage in retrolental fibroplasia. Am J Ophthalmol 1962: 53: $337-45$.

9 Birge HL. Myopia caused by prematurity. Am J Ophthalmol 1956; $41: 292-8$.

10 Kalina RE. Ophthalmic examination of children of low birth weight. Am J Ophthalmol 1969; 67: 134-6.

11 Owens WC. Symposium on retrolental fibroplasia: clinical course. Am J Ophthalmol 1955; 40: 159-62.

12 Jansson F. Measurements of intraocular distances by ultrasound (a survey based on papers by Jonson et al., 1961-3). Acta Ophthalmol (Kbh) 1976; suppl 128: 76-92.

13 Hiatt RL. Costenblader FD. Albert DG. Clinical evaluation of congenital myopia. Arch Ophthalmol 1965; 74: 31-5.

14 Tasman W. Late complication of retrolental fibroplasia. Trans Am Acad Ophthalmol Otolaryngol 1979; 10: 1924-40. 